\title{
A case of severe osteomalacia caused by Tubulointerstitial nephritis with Fanconi syndrome in asymptomotic primary biliary cirrhosis
}

Shintaro Yamaguchi ${ }^{1}$, Tatsuya Maruyama ${ }^{1,5^{*}}$, Shu Wakino ${ }^{1}$, Hirobumi Tokuyama ${ }^{1}$, Akinori Hashiguchi ${ }^{3}$, Shinichiro Tada', Koichiro Homma', Toshiaki Monkawa ${ }^{4}$, James Thomas ${ }^{4}$, Kazutoshi Miyashita ${ }^{1}$, Isao Kurihara ${ }^{1}$, Tadashi Yoshida ${ }^{2}$, Konosuke Konishi ${ }^{1}$, Koichi Hayashi ${ }^{1}$, Matsuhiko Hayashi ${ }^{2}$ and Hiroshi Itoh ${ }^{1}$

\begin{abstract}
Background: Primary biliary cirrhosis (PBC) is an immune-mediated chronic cholestatic liver disease, characterized by increased concentrations of serum IgM and the presence of circulating anti-mitochondrial antibodies. Although bone diseases such as osteoporosis or osteodystrophy are commonly associated with PBC, osteomalacia which is caused by abnormal vitamin D metabolism, mineralization defects, and phosphate deficiency has not been recognized as a complication of PBC.

Case presentation: We report the case of a 49-year-old Japanese woman who complained of multiple fractures. Hypophosphatemic osteomalacia was diagnosed from a low serum phosphorus level, 1,25-dihydroxyvitamin $D_{3}$ level, high levels of bone specific alkaline phosphatase and the findings of bone scintigraphy, although a bone biopsy was not performed. Twenty four hour urine demonstrated a low renal fractional tubular reabsorption of phosphate, increased fractional excretion of uric acid and generalized aminoaciduria. An intravenous bicarbonate loading test suggested the presence of proximal renal tubular acidosis (RTA). These biochemical data indicated Fanconi syndrome with proximal RTA. A kidney biopsy demonstrated the features of tubulointerstitial nephritis (TIN).

The patient was also suspected as having primary biliary cirrhosis (PBC) because of high levels of alkaline phosphatase, $\lg \mathrm{M}$ and the presence of anti-mitochondrial M2 antibody, though biochemical liver function was normal. Sequential liver biopsy was compatible with PBC and the diagnosis of PBC was definite. After administration of 1,25 dihydroxyvitamin $\mathrm{D}_{3}$, neutral potassium phosphate, sodium bicarbonate for osteomalacia and subsequent predonizolone for TIN, symptoms of fractures were relieved and renal function including Fanconi syndrome was ameliorated.

Conclusion: In this case, asymptomatic PBC was shown to induce TIN with Fanconi syndrome with dysregulation of electrolytes and vitamin D metabolism, which in turn led to osteomalacia with multiple fractures. Osteomalacia has not been recognized as a result of the renal involvement of PBC. PBC and its rare complication of TIN with Fanconi syndrome should be considered in adult patients with unexplained osteomalacia even in the absence of liver dysfunction.
\end{abstract}

Keywords: Osteomalacia, Tubulointerstitial nephritis, Fanconi syndrome, Primary biliary cirrhosis, Mitochondrial cytopathy

\footnotetext{
* Correspondence: maruyama@z7.keio.jp

${ }^{1}$ Department of Internal Medicine, Keio University School of Medicine, 35

Shinanomachi, Shinjuku-ku, Tokyo 160-8582, Japan

${ }^{5}$ Center for Clinical Research, Keio University School of Medicine, 35

Shinanomachi, Shinjuku-ku, Tokyo 160-8582, Japan

Full list of author information is available at the end of the article
} 


\section{Background}

Primary biliary cirrhosis (PBC) is an immune-mediated chronic cholestatic liver disease, characterized by nonsuppurative destruction of interlobular bile ducts $[1,2]$. Serologically, $\mathrm{PBC}$ is accompanied by increased concentrations of serum immunoglobulin $\mathrm{M}$ (IgM) and the presence of circulating anti-mitochondrial antibodies [1]. Although bone diseases such as osteoporosis or osteodystrophy, are commonly associated with $\mathrm{PBC}$, osteomalacia, which is caused by abnormal vitamin D metabolism, mineralization defects, and phosphate deficiency, has not been frequently complicated with $\mathrm{PBC}[3,4]$. In renal complication of $\mathrm{PBC}$, distal renal tubular acidosis (RTA) has been reported with the prevalence rates of 30 to $60 \%$ generally in asymptomatic or latent condition $[5,6]$. Tubulointerstitial nephritis (TIN) and subsequent Fanconi syndrome, a type of proximal tubular defects, have been more rarely reported in patients with PBC [7-9].

We report herein a rare case of hypophosphatemic osteomalacia caused by TIN with Fanconi syndrome in asymptomatic PBC. Multiple fractures due to hypophosphatemic osteomalacia were almost ameliorated after the administration of 1,25 dihydroxyvitamin $\mathrm{D}_{3}$, neutral potassium phosphate, and sodium bicarbonate. The renal function also remained stable after subsequent administration of middle-dose corticosteroids.

\section{Case presentation}

In November 2007, a 49-year-old Japanese woman was referred to our hospital from an orthopaedist complaining of a one year history of sustained difficulty walking and severe bilateral hip pain. Her height was $155.5 \mathrm{~cm}$ and body weight was $61.0 \mathrm{~kg}$. Laboratory data showed a creatinine of $1.4 \mathrm{mg} / \mathrm{dl}$, potassium $2.8 \mathrm{mmol} / \mathrm{l}$, calcium $9.5 \mathrm{mg} / \mathrm{dl}$, phosphorus $2.5 \mathrm{mg} / \mathrm{dl}$, uric acid $1.5 \mathrm{mg} / \mathrm{dl}$, normoglycaemic glycosuria and metabolic acidemia ( $\left.\mathrm{pH} 7.30, \mathrm{HCO}_{3}^{-} 17.4 \mathrm{mmol} / \mathrm{l}\right)$ (Table 1). Bilateral transcervical fractures were confirmed by MRI (Fig. 1a) and bone scintigraphy showed multiple hot spots in her joints and ribs, compatible with osteomalacia (Fig. 2). Hypophosphatemic osteomalacia was diagnosed clinically from a low serum level of phosphorus, 1,25-dihydroxyvitamin $\mathrm{D}_{3}(11.0 \mathrm{pg} / \mathrm{dl})$, high levels of bone specific alkaline phosphatase (67.5 IU/l), and the findings of bone scintigram, although a bone biopsy was not performed. Tumor-induced osteomalacia (TIO) was ruled out by total body survey with whole body computed tomography or endoscopic surveillances and a normal blood FGF23 $(22.1 \mathrm{pg} / \mathrm{ml}, 10-50 \mathrm{pg} / \mathrm{ml})$ level.

Urinalysis showed $\mathrm{pH} 6.0$ and twenty four hour urine demonstrated a low renal fractional tubular reabsorption of phosphate (Tmp/GFR 0.91), increased fractional excretion of uric acid (FEUA $43.9 \%$ ) and generalized aminoaciduria.
Table 1 Baseline data of the patient on admission in November 2007

\begin{tabular}{|c|c|}
\hline Peripheral blood & Urinalysis \\
\hline $\begin{array}{l}\text { white blood cell count } \\
6800 / \mu l\end{array}$ & $\mathrm{pH} 6.0$ \\
\hline hemoglobin $13.5 \mathrm{~g} / \mathrm{dl}$ & protein $(3+)$ \\
\hline platelet $20.1 \times 10^{4} / \mu \mathrm{l}$ & urine sugar (4+) \\
\hline \multicolumn{2}{|l|}{ Biochemistry } \\
\hline total protein $8.7 \mathrm{~g} / \mathrm{dl}$, & $\begin{array}{l}\text { bone specific alkaline phosphatase } \\
67.5 \mathrm{IU} / \mathrm{l}\end{array}$ \\
\hline albumin $4.6 \mathrm{~g} / \mathrm{dl}$ & Y-glutamyl transpeptidase $18 \mathrm{IU} / \mathrm{I}$ \\
\hline total bilirubin $0.7 \mathrm{mg} / \mathrm{dl}$ & 1,25-dihydroxyvitamine D 11.0 pg/dl \\
\hline $\begin{array}{l}\text { blood urea nitrogen } \\
19.4 \mathrm{mg} / \mathrm{dl}\end{array}$ & intact parathyroid hormone $46 \mathrm{pg} / \mathrm{ml}$ \\
\hline creatinine $1.4 \mathrm{mg} / \mathrm{dl}$ & $\begin{array}{l}\text { parathyroid hormone-related protein } \\
<1.1 \mathrm{pg} / \mathrm{ml}\end{array}$ \\
\hline uric acid $1.5 \mathrm{mg} / \mathrm{dl}$ & calcitonin 24 pg/ml \\
\hline sodium $137.8 \mathrm{mEq} / \mathrm{l}$ & osteocalcin $7.6 \mathrm{ng} / \mathrm{ml}$ \\
\hline potassium $2.8 \mathrm{mEq} / \mathrm{l}$ & fibroblast growth factor-23 $22.1 \mathrm{pg} / \mathrm{ml}$ \\
\hline chloride 108 mEq/l & $\operatorname{lgG} 1228$ mg/dl \\
\hline calcium 9.5 mg/dl & $\operatorname{lgA} 201$ mg/dl \\
\hline phosphorus 2.3 mg/dl & lgM 1084 mg/dl \\
\hline $\begin{array}{l}\text { fasting plasma glucose } \\
98 \mathrm{mg} / \mathrm{dl}\end{array}$ & anti-nuclear antibody 1:1280 \\
\hline hemoglobin $A_{1 c} 4.8 \%$ & anti-SS-A/Ro antibody (-) \\
\hline total cholesterol $249 \mathrm{mg} / \mathrm{dl}$ & anti-SS-B/La antibody (-) \\
\hline $\begin{array}{l}\text { c-reactive protein } 0.17 \\
\mathrm{mg} / \mathrm{dl}\end{array}$ & $\begin{array}{l}\text { anti-double stranded DNA antibody } \\
3 \mathrm{IU} / \mathrm{ml}\end{array}$ \\
\hline $\begin{array}{l}\text { lactate dehydrogenase } \\
191 \text { IU/I }\end{array}$ & Shirmer test $(-)$ \\
\hline $\begin{array}{l}\text { aspartate aminotransferase } \\
23 \mathrm{IU} / \mathrm{l}\end{array}$ & serum M protein(-) \\
\hline $\begin{array}{l}\text { alanine aminotransferase } \\
24 \mathrm{IU} / \mathrm{I}\end{array}$ & urine Bence Jones Protein (-) \\
\hline $\begin{array}{l}\text { alkaline phosphatase } \\
663 \mathrm{IU} / \mid\end{array}$ & $\begin{array}{l}\text { anti-mitochondrial } \mathrm{M}_{2} \text { antibody } 10.0 \\
\text { index }\end{array}$ \\
\hline $\begin{array}{l}\text { Arterial blood gas analysis } \\
\text { (Room Air) }\end{array}$ & 24-h urine analysis \\
\hline pH 7.306 & Tmp/GFR 0.91 \\
\hline $\mathrm{pO}_{2} 89.0$ torr & \%TRP $37.9 \%$ \\
\hline $\mathrm{pCO}_{2} 35.9$ torr & FEUA $43.9 \%$ \\
\hline $\mathrm{HCO}_{3}^{-} 17.4 \mathrm{mmol} / \mathrm{l}$ & glucose $12.83 \mathrm{~g}$ \\
\hline bicarbonate loading test & generalized aminoaciduria(+) \\
\hline $\mathrm{FEHCO}_{3}^{-} 13.25 \%$ & protein $2.464 \mathrm{~g}$ \\
\hline \multirow[t]{2}{*}{ U-Bpco $250.1 \mathrm{mmHg}$} & FEca 11.878 \%, \\
\hline & $\mathrm{CrCl} 45.76 \mathrm{ml} / \mathrm{min} / 1.73 \mathrm{~m}^{2}$ \\
\hline
\end{tabular}

The calculated anion gap was $12.4 \mathrm{meq} / \mathrm{l}$, with an inappropriately alkaline urine ( $\mathrm{pH}$ 6.0), suggestive of distal type of renal tubular acidosis (RTA). An intravenous bicarbonate loading test to assess the tubular dysfunction 


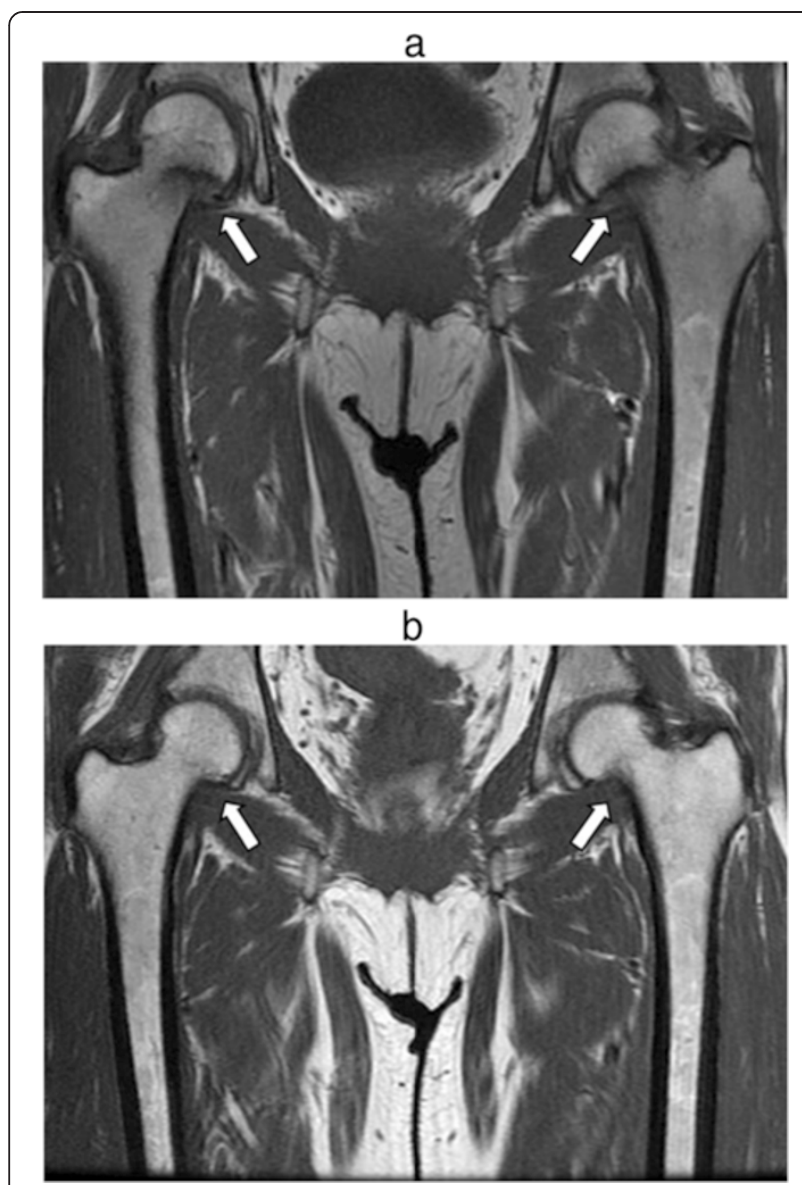

Fig. $1 \mathrm{MRI}$ findings of incomplete bilateral transcervical fractures (Arrows) before (a) and after (b) the treatment

demonstrated that the increased fractional excretion of bicarbonate ( $\left.\mathrm{FEHCO}_{3}^{-} 13.25 \%\right)$ and urine-blood (UB) $\mathrm{PCO}_{2}$ gradient $\left(\mathrm{U}-\mathrm{Bpco}_{2} 50.1 \mathrm{mmHg}\right)$, suggesting the presence of proximal type of $\mathrm{RTA}$. $\mathrm{NH}_{4} \mathrm{Cl}$ loading test was not performed because of the presence of apparent metabolic acidemia. These biochemical data of blood and urine indicated Fanconi syndrome with proximal type of RTA. Tests for anti-SSA and anti-SSB were negative and serum angiotensin converting enzyme levels were normal. Furthermore, serum and urine immunoelectrophoresis revealed no monoclonal component. Any of the patient's medication did not seem to be related to Fanconi syndrome. Light microscopic examination of a kidney biopsy demonstrated cellular infiltration of interstitium and proximal tubular epithelium composed mainly of $\mathrm{CD}_{3}^{+}$lymphocytes without glomerular involvement, consistent with features of TIN (Fig. 3a ,b).

The patient was also suspected to be diagnosed as PBC because of high levels of alkaline phosphatase (663 IU/l), high serum IgM levels $(1084 \mathrm{mg} / \mathrm{dl})$ and the presence of anti-mitochondrial M2 antibody (1:10). Sequential liver biopsy demonstrated the presence of a

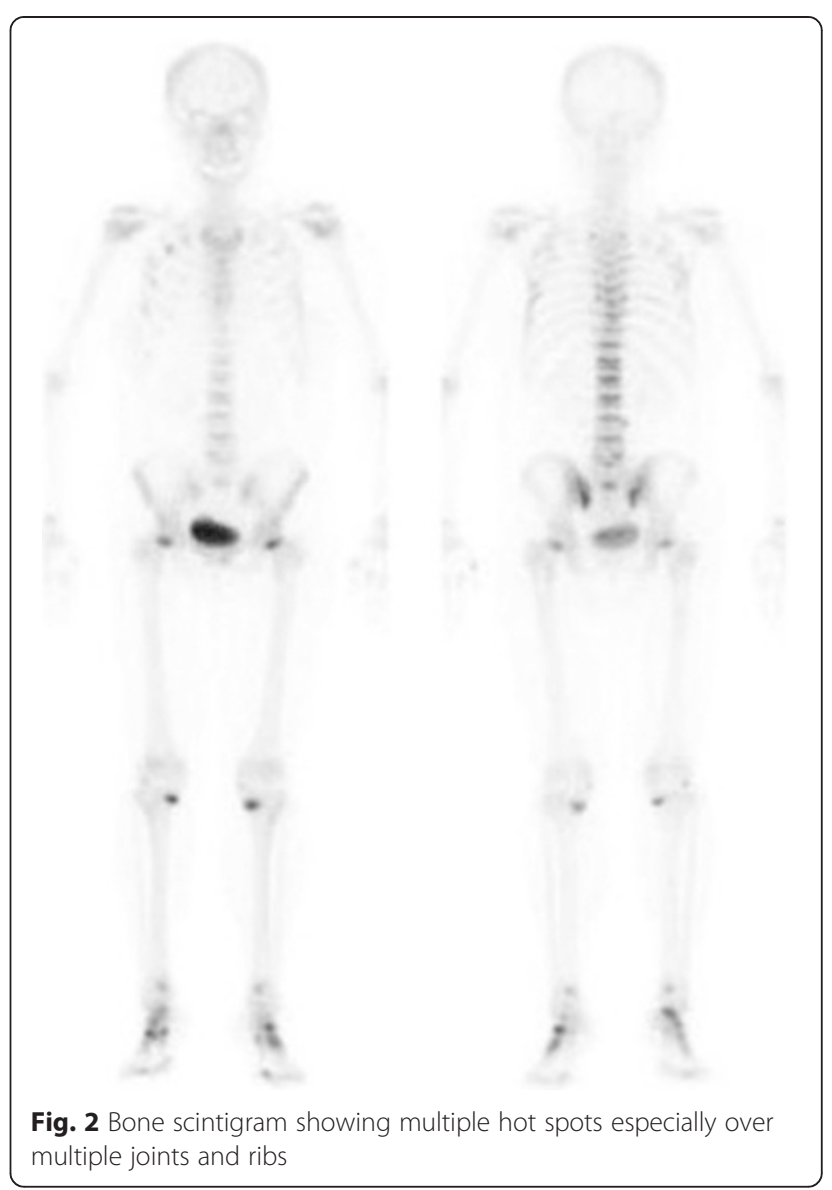

periportal cellular infiltrate (Fig. 3c), compatible with $\mathrm{PBC}$ though biochemical liver function was normal. The combination of these findings led to the patient's diagnosis of osteomalacia caused by TIN with Fanconi syndrome in asymptomatic PBC.

The patient was started on therapy with calcitriol $(1 \mu \mathrm{g} /$ day), neutral potassium phosphate and sodium bicarbonate (6 g/day). She was subsequently administered middledose corticosteroid (20 mg/day of predonisolone) and ursodeoxycholic acid (300 mg/day). One year after the treatment, the patient became asymptomatic and renal function remained stable. Furthermore, MRI showed the bilateral transcervical fractures of the femoral neck had almost fully repaired (Fig. 1b). Treatment is currently being continued in the outpatient clinic.

\section{Discussion}

We described a severe osteomalacia caused by TIN with Fanconi syndrome in asymptomatic PBC. Although osteomalcia is rarely observed in patients with PBC [4], malabsorption as a consequence of severe cholestasis and impaired ability to convert vitamin D to 25hydroxivitamin $\mathrm{D}$ can cause osteomalacia in patients with advanced $\mathrm{PBC}[10,11]$. Our case was unique in 


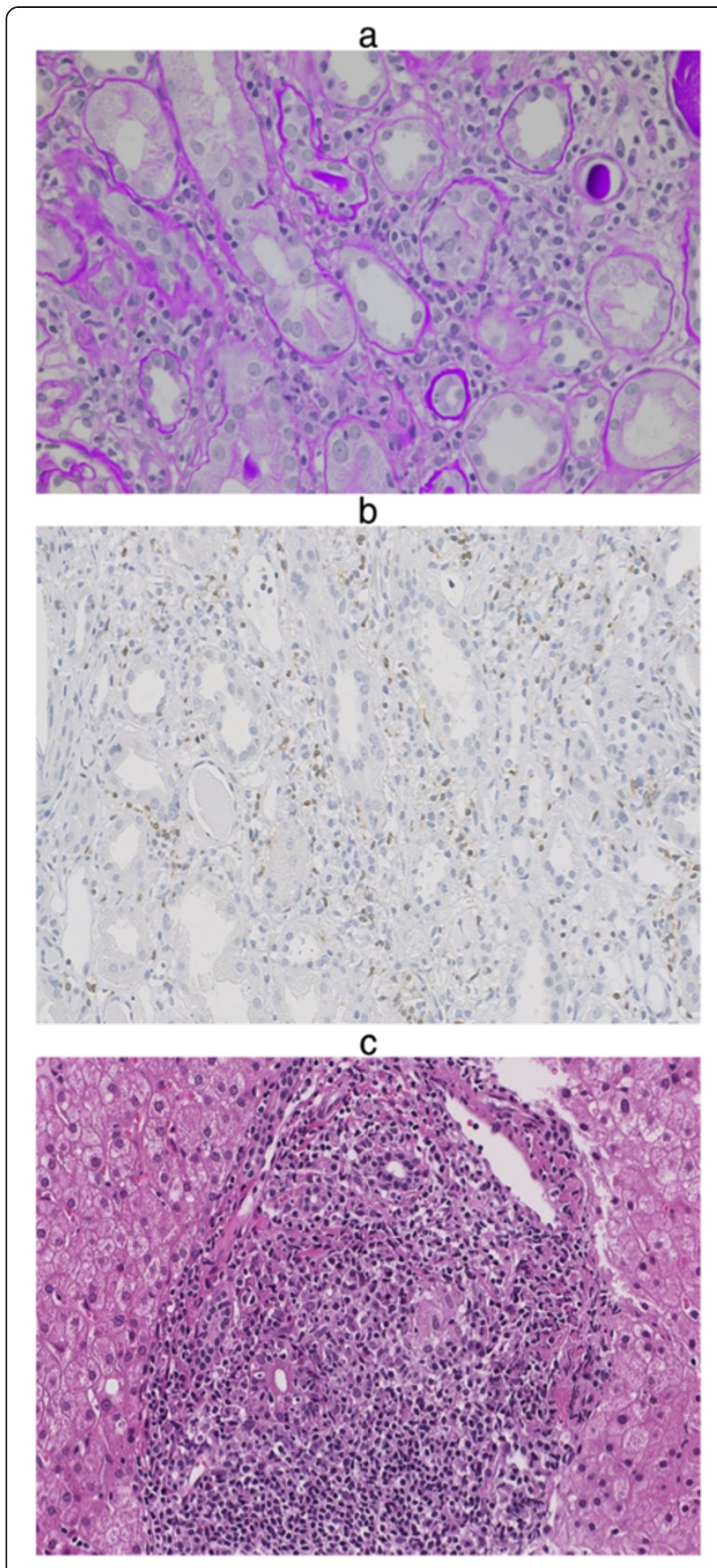

Fig. 3 The Findings of Kidney and Liver Biopsies. a, b Kidney biopsy specimen; light microscopy shows (a) cellular infiltration in the proximal tubules and interstitium, and the presence of atrophic tubules (Hematoxylin-eosin staining) and (b) $\mathrm{CD}_{3}^{+}$cells infiltration in the renal interstitium. c Liver biopsy specimen; light microscopy shows the presence of a periportal cellular infiltrate

that osteomalacia developed as a result of the rare renal involvement of asymptomatic $\mathrm{PBC}$.

Osteomalacia is accelerated by inadequate renal phosphorus wasting and decreased uptake of active vitamin $\mathrm{D}$ as well as a decrease in $1 \alpha$-hydroxylation of vitamin $\mathrm{D}$
$[12,13]$. The serum concentration of 1,25 dihydroxyvitamin $D_{3}$ which reflects the regulation of $1 \alpha$-hydroxylation of vitamin D in the kidney is impaired in renal tubular diseases such as Fanconi syndrome $[14,15]$. This patient had a low circulating level of 1,25 dihydroxyvitamin $\mathrm{D}_{3}$ which is presumed to be caused by Fanconi syndrome. Indeed, osteomalacia is a well-observed consequence of the Fanconi syndrome [16]. Fanconi syndrome also complicated with chronic hypophosphatemia and chronic acidemia, which considered to cause and aggravate osteomalacia $[7,17]$.

It is suggested that hepatic dysfunction is not implicated in the pathogenesis of TIN, while on the other hand, TIN in the present case may be pathogenically related to $\mathrm{PBC}$ [7]. First, lymphocytic infiltration is a pathological mutual feature of TIN and PBC. Autoreactive $\mathrm{T}$ lymphocytes of the tubular epithelium and interstitium may be driven by abnormal antigen expression such as mitochondrial antigen in hepatocytes and renal tubular cells [18]. T lymphocytes of the tubular epithelium are likely to be involved in the inhibition of proximal tubular function, leading to Fanconi syndrome. Second, Anti$\mathrm{M}_{2}$ antibody in patients with $\mathrm{PBC}$ could interfere with intrarenal three mitochondrial enzymes: pyruvate dehydrogenase complex, branched-chain $\alpha$-keto acid dehydrogenase complex and $\alpha$-keto glutamate dehydrogenase complex [7, 9, 19]. Fanconi syndrome and TIN are typical renal features of mitochondrial cytopathies [20]. Although much remains to be elucidated about the pathogenesis of $\mathrm{PBC}$ and its extrahepatic complication of TIN with Fanconi syndrome, circulating anti-mitochondrial $\mathrm{M}_{2}$ antibody would induce PBC and TIN with Fanconi syndrome. Since the usual causes of Fanconi syndrome including metal intoxication were not confirmed, this patient was considered to have PBC-related TIN with Fanconi syndrome.

In summary, severe osteomalacia was considered to be caused by the rare renal involvement of asymptomatic $\mathrm{PBC}$, which is TIN with Fanconi syndrome.

\section{Conclusions}

Herein, the authors present a unique case of osteomalacia developed as a result of the rare renal involvement of asymptomatic PBC. As the prevalence of osteomalacia is increasing in aged societies where homebound elderly patients suffer from nutritional insufficiency, lack of sun exposure, medical histories of gastrointestinal surgery, and the possibility of malignancy, careful inspection for the cause of multiple fractures is necessary. We suggest that $\mathrm{PBC}$ and its rare complication of TIN with Fanconi syndrome should be considered in adult patients with unexplained osteomalacia even in the absence of liver function tests abnormalities. 


\section{Consent}

Written informed consent was obtained from the patient for publication of this case report and any accompanying images. A copy of the written consent is available for review by the Editor of this journal.

\section{Abbreviations \\ IgM: immunoglobulin M; PBC: Primary biliary cirrhosis; RTA: renal tubular acidosis; TIN: tubulointerstitial nephritis; TIO: Tumor-induced osteomalacia.}

\section{Competing interests}

The authors declare that they have no competing interests.

\section{Authors' contributions}

Designated authors meet all four criteria for authorship in the ICMJE recommendations. Individual contribution of each authors are as follows. SY and TM treated the patient as an inpatient and made decisions about patient's examinations and therapies. SY and TM reviewed previous publications and wrote the whole manuscript. SW, HT are nephrologists at Keio University Hospital and performed the renal biopsy of the patient. SW is an associate professor of nephrology at Keio University Hospital and supervised the manuscript. KK is a director of renal pathology at Keio University Hospital and performed the evaluation of the renal biopsy. $\mathrm{AH}$ is a pathologist and an assistant professor of pathology at Keio University Hospital. AH made sections of all renal biopsy samples, took pictures of renal pathology and read patient's renal pathology. ST is a gastroenterologist at Keio University Hospital and performed the liver biopsy of the patient. KH, TM, KM, IK, TY, KH, JT contributed to the interpretation of the etiology and discussion. $\mathrm{MH}$ is a professor of dialysis center at Keio University Hospital. MH is a principal physician of the patient and treated her as an inpatient and outpatient. $\mathrm{HI}$ is a professor of nephrology, endocrinology and metabolism, and supervised the manuscript. All authors read and approved the final manuscript.

\section{Author details}

${ }^{1}$ Department of Internal Medicine, Keio University School of Medicine, 35 Shinanomachi, Shinjuku-ku, Tokyo 160-8582, Japan. ${ }^{2}$ Apheresis and Dialysis Center, Keio University School of Medicine, 35 Shinanomachi, Shinjuku-ku, Tokyo 160-8582, Japan. ${ }^{3}$ Department of Pathology, Keio University School of Medicine, 35 Shinanomachi, Shinjuku-ku, Tokyo 160-8582, Japan. ${ }^{4}$ Medical education Center, Keio University School of Medicine, 35 Shinanomachi, Shinjuku-ku, Tokyo 160-8582, Japan. ${ }^{5}$ Center for Clinical Research, Keio University School of Medicine, 35 Shinanomachi, Shinjuku-ku, Tokyo 160-8582, Japan.

Received: 16 June 2015 Accepted: 3 November 2015 Published online: 11 November 2015

\section{References}

1. Talwalkar JA, Lindor KD. Primary biliary cirrhosis. Lancet. 2003;362:53-61.

2. Kaplan MM. Primary biliary cirrhosis. N Engl J Med. 1987;316:521-8.

3. Reginster JY. The high prevalence of inadequate serum vitamin D levels and implications for bone health. Curr Med Res Opin. 2005;21:579-85.

4. Mounach A, Ouzzif Z, Wariaghli G, Achemlal L, Benbaghdadi I, Aouragh A, et al. Primary biliary cirrhosis and osteoporosis: a case-control study. J Bone Miner Metab. 2008;26:379-84.

5. Farias AQ, Goncalves LL, Cancado EL, Seguro AC, Campos SB, Abranteslemos $C P$, et al. Bone disease in primary biliary cirrhosis: Lack of association with distal renal tubular acidosis. J Gastroenterol Hepatol. 2005;20:147-52.

6. Golding PL, Mason ASM. Renal tubular acidosis and autoimmune liver disease. Gut. 1971:12:153-7.

7. Lino M, Binaut R, Noël LH, Patey N, Rustin P, Daniel L, et al. Tubulointerstitial nephritis and Fanconi syndrome in primary biliary cirrhosis. Am J Kidney Dis. 2005;46:e41-6.

8. Komatsuda A, Wakui H, Ohtani H, Masai R, Okuyama S, Nimura T, et al. Tubulointerstitial nephritis and renal tubular acidosis of different types are rare but important complications of primary biliary cirrhosis. Nephrol Dial Transplant. 2010;25:3575-9.

9. Kodama T, Imai H, Wakui H, Ohtani H, Komatsuda A, Miura AB. Tubulointerstitial nerphritis with renal tubular acidosis and asymptomatic primary biliary cirrhosis accompanied by antibody to a 52-kDa mitochondrial protein alone. Clin Nephrol. 1996:45:401-5.

10. Bando H, Hashimoto N, Hirota Y, Sakaguchi K, Hisa I, Inoue Y, et al. Severe hypophosphatemic osteomalacia with Fanconi syndrome, renal tubular acidosis, vitamin D deficiency and primary biliary cirrhosis. Intern Med. 2009;48:353-8.

11. Hay JE. Bone disease in cholestatic liver disease. Gastroenterology. 1998;108:276-83.

12. Clarke BL, Wynne AG, Wilson DM, Fitzpatrick LA. Osteomalacia associated with adult Fanconi's syndrome: clinical and diagnostic features. Clin Endocrinol (Oxf). 1995;43:479-90.

13. Holick MF. Vitamin D deficiency. N Engl J Med. 2007;357:266-81.

14. Portale AA, Miller WL. Human 25-hydroxyvitamin D-1a-hydroxylase: cloning, mutations, and gene expression. Pediatr Nephrol. 2000;14:620-5.

15. Magen D, Adler L, Mandel H, Efrati E, Zelikovic I. Autosomal recessive renal proximal tubulopathy and hypercalciuria: a new syndrome. Am J Kidney Dis. 2004:43:600-6.

16. Verhelst D, Monge M, Meynard $J$, Fouqueray B, Mougenot B, Girard PM, et al. Fanconi syndrome and renal failure induced by tenofovir: a first case report. Am J Kidney Dis. 2002;40:1331-3.

17. Terrier B, Fakhouri F, Berezne A, Bouldouyre MA, Guilpain P, Sogni P, et al. Osteomalacia revealing celiac disease and primary biliary cirrhosis-related Fanconi syndrome in a patient with systemic sclerosis. Clin Exp Rheumatol. 2008:26:467-70

18. Poupon R, Poupon RE. Retrovirus infection as a trigger for primary biliary cirrhosis? Lancet. 2004;363:260-1.

19. Gershwin ME, Mackay IR. Primary biliary cirrhosis: paradigm or paradox for autoimmunity. Gastroenterology. 1991;100:822-33.

20. Niaudet $P$, Rotig A. The kidney in mitochondrial cytopathies. Kidney Int. 1997:51:1000-7.

\section{Submit your next manuscript to BioMed Central and take full advantage of:}

- Convenient online submission

- Thorough peer review

- No space constraints or color figure charges

- Immediate publication on acceptance

- Inclusion in PubMed, CAS, Scopus and Google Scholar

- Research which is freely available for redistribution

Submit your manuscript at www.biomedcentral.com/submit
C Biomed Central 